\title{
Cuando la historia y el patrimonio invaden la pantalla. Diálogo con Javier Olivares
}

\section{When history and heritage invade the screen. Dialogue with Javier Olivares}

\author{
Sebastián Alberto Longhi Heredia \\ Universidad de Huelva, España \\ slonghi7@yahoo.com.ar \\ https://orcid.org/o000-0001-8438-562X \\ María Aurora Forteza Martínez \\ Universidad de Huelva, España \\ afortezama@gmail.com \\ https://orcid.org/0000-0001-9680-5927
}

\section{Resumen:}

El proceso de creación y producción de las series de ficción históricas en España ha mostrado un notorio crecimiento durante los últimos años. Con Isabel (20122014), Víctor Ros (2015-2016) y El Ministerio del Tiempo (2015-2020) Javier Olivares y su hermano han logrado dar vida a un universo único logrando invadir la pantalla de personajes históricos ligados al patrimonio cultural español. Olivares, uno de los más importantes productores y guionistas de la ficción española de nuestros días, habla en esta entrevista de la lógica de realización de las series ficcionales e históricas. Se detallan además cuestiones ligadas a la (re)producción y a la (re)creación de figuras emblemáticas del arte y la historia de España, su proceso de construcción estético, su grado de alcance e impacto en la sociedad, así como las perspectivas futuras del productor.

\begin{abstract}
:
In recent years, the genre of historical fiction has seen notable growth in Spanish television. With Isabel (2012-2014), Víctor Ros (2015-2016) and El Ministerio del Tiempo (2015-2020), Javier Olivares manages to give life to a unique universe, managing to invade viewers' screens with historical characters linked to Spanish cultural heritage. Olivares, one of the most important producers and scriptwriters of Spanish fiction today, talks about the logic behind the production of fictional and historical series in this interview. Issues related to the (re) production and (re) creation of emblematic figures in the art and history of Spain, their aesthetic construction process, their degree of scope and thier impact on society, as well as the producer's upcoming projects.
\end{abstract}

Palabras clave: Olivares, Javier; Series; Historia de España, Patrimonio Cultural, Ficción Histórica, Representaciones Sociales

Keywords: Olivares, Javier; Serials; History of Spain, Cultural Heritage, Historical Fiction, Social Representations 


\section{Introducción}

Durante los últimos años, numerosos trabajos se han interesado en estudiar la lógica de reproducción de representaciones socioculturales a través de las series de televisión, prestado especial interés a la creación de contenido ficcional e histórico. Las producciones perpetradas en las últimas décadas en España evidencian un profundo intereses en (re)producir contenido ficcional, partiendo de los hechos acaecidos en el pasado. Estas series han logrado posicionarse adoptando una realidad icónica subjetiva que transmite ciertos estereotipos asociados a la construcción de imaginarios o significados sociales (Berger et al., 1968; Castoriadis, 2007 y Leyton-Rivas, 2007).

España denota una preocupación por encarar esta realidad mediante la producción fundada en un cierto rigor histórico, característica fundamental en la creación de personajes y escenarios. La tendencia demuestra un profundo interés en retratar el pasado partiendo de la (re)creación de personajes y escenarios en relación con el patrimonio cultural, un boom que ha sido aclamado por la crítica y los espectadores, situación que ha provocado un mayor interés en este tipo de series. Su lógica de producción comercial se apoya en cuotas de audiencia significativas como lo han atestiguado algunas de las series con trasfondo histórico más vistas en España: Curro Jiménez (TVE, 1976-1978/1995), Amar en tiempos revueltos (TVE, 2005-2012), Amar es para siempre (Antena3, 2017-2021), La Señora, (TVE, 2008-2010) Tiempos de Guerra (Antena 3, 2017), El tiempo entre costuras (Antena 3, 2013-214), Águila Roja (TVE, 2009-2016), Las chicas del cable (Netflix 2017-2020). De la misma manera, el tratamiento de cuestiones históricas en series ficcionales ha impactado de manera positiva en la audiencia, series como Cuéntame cómo pasó (TVE, 2001-2021), Isabel (TVE, 2012-2014), Víctor Ros (TVE, 2015), 14 de abril, La República (TVE, 2011/2018-2019), Carlos, rey emperador (TVE, 2015-2016), La Catedral del Mar (Antena 3, 2018), El Ministerio del Tiempo (TVE, Netflix y HBO, 20152020), Patria (HBO España, 2020), El Cid (Amazon Prime Vídeo, 2020), Dime quién soy (Movistar+, 2020-2021) reflejan esta situación. Este interés 
ha traspasado las fronteras y generado colaboraciones con otros países del calibre de Réquiem por Granada (TVE- RAI, 1999), Reinas (RTVE y BBC, 2017), e Inés Alma mía (RTVE, Boomerang TV y Chilevisión, 2019).

En este universo de producción ficcional se destaca la figura de Javier Olivares, gran exponente en materia de difusión de cultura y patrimonio, no ya de producciones con trasfondo histórico, sino basadas en la macro y microhistoria. Junto a su hermano Pablo, han sido los precursores de un género que ha sido todo un éxito, consiguiendo influenciar y trastocar diferentes sectores de la realidad cotidiana. Sus producciones han suscitado la atención de la audiencia, repercutiendo positivamente en la industria del turismo, en las redes sociales, en el ámbito de la transmedia, trascendiendo el espacio nacional.

Con Isabel, Víctor Ros, y El Ministerio del Tiempo (EMDT), la ficción histórica española se consolida como una fórmula de éxito. En términos de Olivares, en esta "trilogía” la representación social de pintores, reyes, figuras históricas y del patrimonio español (en cuadros y monumentos) adquiere mayor visibilidad ya que la labor constructiva sigue un proceso concreto de creación anclado en el uso de fuentes oficiales (patrimonio bibliográfico del pueblo español). El resultado final ha sido (re)construido, (re)pensado y (re)transmitido en vistas a dos objetivos: entretener y educar divulgando la historia, representando el patrimonio y generando una consciencia crítica del valor del pasado, en el presente, pensando en el futuro. En este sentido en diálogo con Olivares se ha podido dilucidar la fórmula de éxito que ha convertido a los personajes históricos en un fenómeno de moda, en Trending Topic y en representaciones sociales del pasado que se quedarán grabadas en el futuro en la mente de todos aquellos que consagraron una hora semanal al disfrute de este tipo de contenido. 


\section{El pasado y el presente por la memoria futura}

Ya sea este universal, nacional o regional, el patrimonio existe para mostrarnos unas ciertas características que le han otorgado ese valor simbólico por el cual debemos disfrutarlo... Si hay algo que caracteriza tus series es el interés por el patrimonio. ¿Qué representa este concepto para tí?

Yo creo que hay un patrimonio artístico, humanístico y cultural, y no sólo depende de ese concepto de arte con mayúsculas, sino que también incorpora el patrimonio popular tradicional, las costumbres como por ejemplo la cerámica. El patrimonio es una antropología más o menos moderna del arte. En él, es casi tan importante Lope de Vega, Camarón, Lorca, Joan Manuel Serrat como Mozart.

Quitando ese mirar por encima del hombro a la cultura pop, esa cultura -que parece que está guardada en un museo con una llave secreta y que sólo pueden explicar expertos y especialistas-, es tan importante como la otra. El patrimonio cultural es todo eso.

La (re)creación de personajes históricos y de guiones son etapas fundamentales del proceso de producción audiovisual. En tu caso ¿Qué has tenido en cuenta a la hora de trazar el escenario histórico en las series?

En la primera temporada del Ministerio del Tiempo, con Pablo tratamos los hechos como historiadores que somos. Nos basamos en una seriedad de la documentación histórica.

Veníamos de hacer la primera temporada de Isabel que tiene más de un 90\% de rigor histórico en cada capítulo, con no menos de 20 frases por capítulo. En la serie había situaciones sacadas directamente de los diálogos de las crónicas de la época, o de la transformación de las cartas, Luego hicimos Víctor Ros, un paso más allá en cuanto a la adaptación literaria. Aquí hablamos de una época, de la pérdida de la España antes de 1898, de Antonio Cánovas del Castillo y Práxedes Mateo Sagasta, Pío Baroja, y Benito Pérez 
Galdós. Ya en EMDT lo adaptamos a una serie de aventuras. En la primera temporada elegimos símbolos y temas históricos que dominábamos. A partir de ahí, entró la búsqueda del momento histórico que podía significar algo y definir nuestro presente en base al pasado. Así encontramos la desigualdad de la mujer, los héroes anónimos, los perdedores y los desaparecidos. A partir de todo eso hablamos del ahora yendo al pasado, pero no imaginando un pasado reescrito como nos convendría, porque la labor del Ministerio, y su lema es que el pasado no se reescribe.

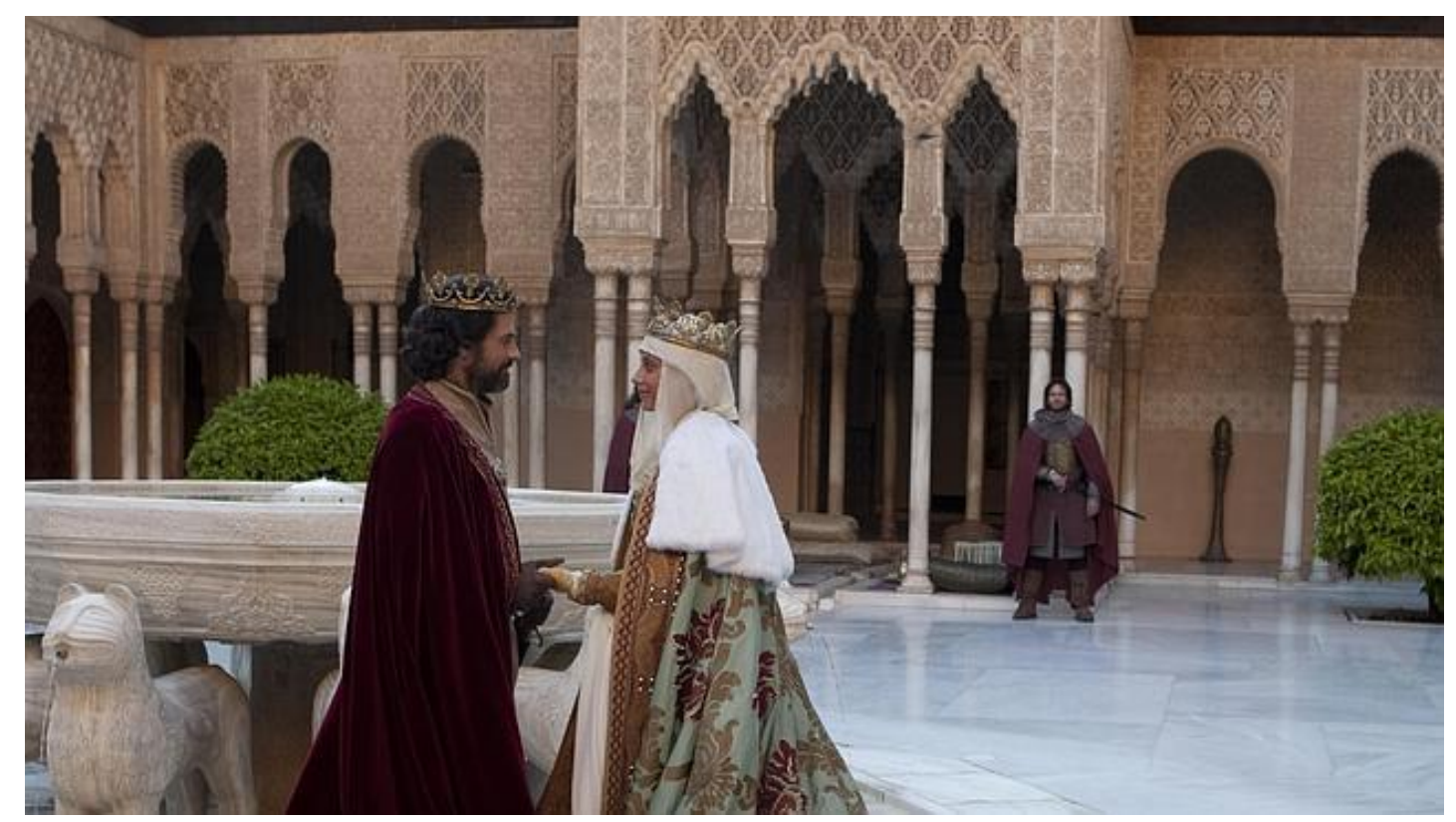

Fotograma de la serie Isabel rodada en el espacio patrimonial de la Alhambra. (C) TVE.

\section{En lo relativo al proceso de producción ¿̇Te arrepientes o reconsiderarías modificar algo?}

El hecho de que EMDT estuviera paralizado tanto tiempo. Siento no haber podido tener más continuidad, porque a esta estas series que son tan culturales, o se las miman o es muy difícil de volver a levantarlas. Al mismo tiempo estoy chocado de no haber podido hacer mi serie de Felipe II, de no ver una adaptación de los episodios nacionales de Benito Péres Gardós. Para mi hay un déficit en ese sentido, y me da mucha pena, porque muchos debates de los que ahora se cuentan, no estarían discutiéndose tanto. 


\section{Como dices hay un antes y un después con Isabel ¿Cuáles han sido las semejanzas y diferencias con EMDT?}

Pues con una serie un poco más pequeñita y modesta que fue Víctor Ros entre medio, las tres forman una trilogía sobre España. Esto ya lo comentó Conchi Cascajosa ${ }^{1}$, experta en series.

En Isabel trabajamos el origen de muchas cosas, antes de que España fuera España. Luego esa España en crisis en Victor Ros, que de repente huye de la ciencia y de lo moderno, y que tanto recuerda a la de ahora, y por último EMDT que es un poco todas las Españas. Se trata de una trilogía para hablar de nosotros, para saber cómo éramos. Lo que nosotros hemos hecho es unificar el concepto de la tercera España que no está peleada como la otras dos. En el caso de Isabel contamos una historia de manera dura, muy rigurosa de la parte que me tocó, pero que representaba a todos.

Las tres fueron pensadas con estilos y géneros distintos, pero la idea en común es que somos españoles, entonces vamos a hablar de España y a valorar lo que somos, que en ese sentido no lo hacemos lo suficiente; y también vamos a criticar lo que hemos hecho mal y los orígenes del horror. En este sentido hay dos capítulos esenciales en EMDT, uno es el del Cid, y otro el de Felipe II (el del cambio del tiempo). Desde allí se tratan los conceptos de una manera muy crítica, que incluso en el caso de Felipe II pocos hablaron porque era muy duro. Aunque lo traté en forma de comedia, de lo que se estaba hablando era de aquellos que defendían volver al pasado histórico, al momento de la primera potencia, pero un país donde las mujeres no tuvieron derecho y dónde no hubo constitución.

\section{Para muchos con Isabel ya has hecho historia. Gracias a tus creaciones la gente ha (re)descubierto la historia y el patrimonio ¿Qué sensación te provoca este tipo de fenómenos?}

Gracias por el comentario. Yo creo, por lo que me llega de la gente que la serie llega. Por un lado están las mediciones de audiencia, este impacto

\footnotetext{
${ }^{1}$ En alusión a Concepción Cascajosa Virino, investigadora en la Universidad Carlos III, España.2
} 
popular ahora mismo es algo más difuso, porque hay unas maquinitas que lo miden, pero por otro lado están las redes sociales y unas plataformas que no se miden por las maquinitas. Es decir, está todo enmarañado: cuando conviene hablar de YouTube se lo hace, cuando viene bien hablan de las redes, también. A mí me han llegado decenas y decenas de mensajes de padres que dicen que ven la serie con sus hijos; también de institutos donde se pone EMDT como material didáctico; incluso, hemos aparecido ya en libros de texto. Entonces, evidentemente estamos llegando a esas generaciones jóvenes.

\section{En este sentido ¿Cómo fue trabajar con obras artísticas de gran calibre, como el Guernica?}

Pablo y yo tratamos el tema del Guernica en su día en la primera temporada del Ministerio del Tiempo y aunque hubo mucha gente dijo que fue una tontería, lo cual no es verdad; el hecho de que el Guernica volviera a España después de que Picasso exigiera que no volvería jamás a España si no hubiera un gobierno democrático, fue el símbolo de que la democracia existía en España, no ya el cuadro normal y corriente. En cuanto a su aparición en la serie, este fue reconstruido mediante técnicas de $\mathrm{VFX}^{2}$, no estuvimos para nada ahí.

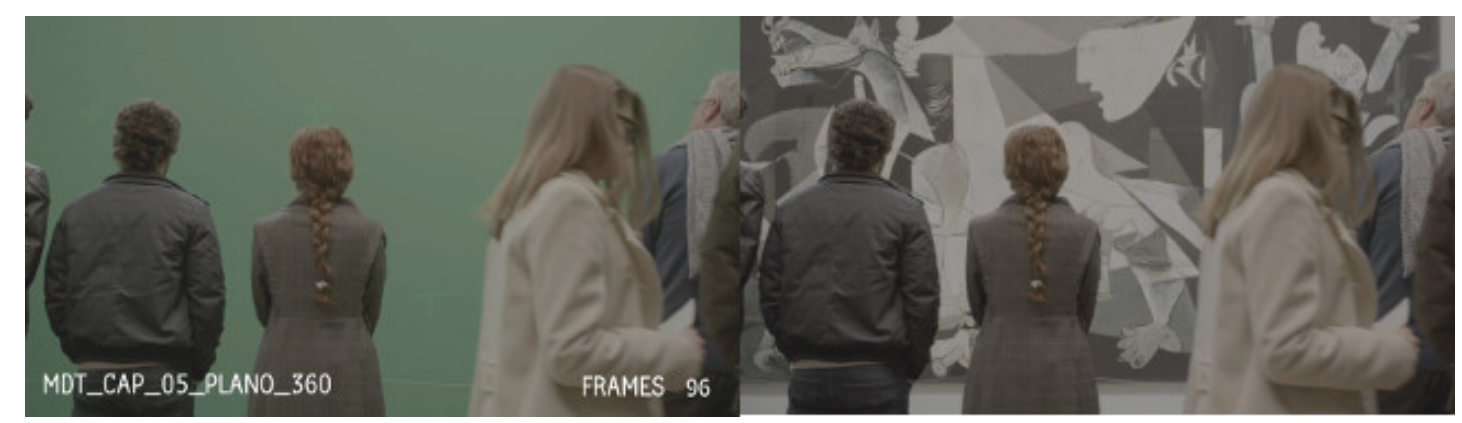

Reproducción del Cuadro "El Guernica” mediante la técnica VFX. (C) USER T38

\footnotetext{
${ }^{2}$ La técnica de los efectos visuales o VFX (en sus siglas en inglés) implica incorporar efectos visuales a una obra audiovisual para simular y recrear escenarios.
} 
Respecto a los rodajes ¿Cómo se trabaja en lugares de fuerte impronta histórica y patrimonial como El Prado o la Granja de San Ildefonso?

Yo no pude estar en El Prado, porque había que tener un equipo mínimo. Preferí que fueran los directores y técnicos. Me sacrifiqué, y me dio mucha rabia pero bueno Julián [Rodolfo Sánchez] y Velázquez [Julián Villagrán] decían que verse delante de Las Meninas era algo espectacular, y me contaron una anécdota muy graciosa, de cómo toda la gente que había allí del equipo del Museo del Prado, les pedían hacerse fotos delante de Las Meninas, con lo cual es como un viaje de ida y vuelta maravilloso.

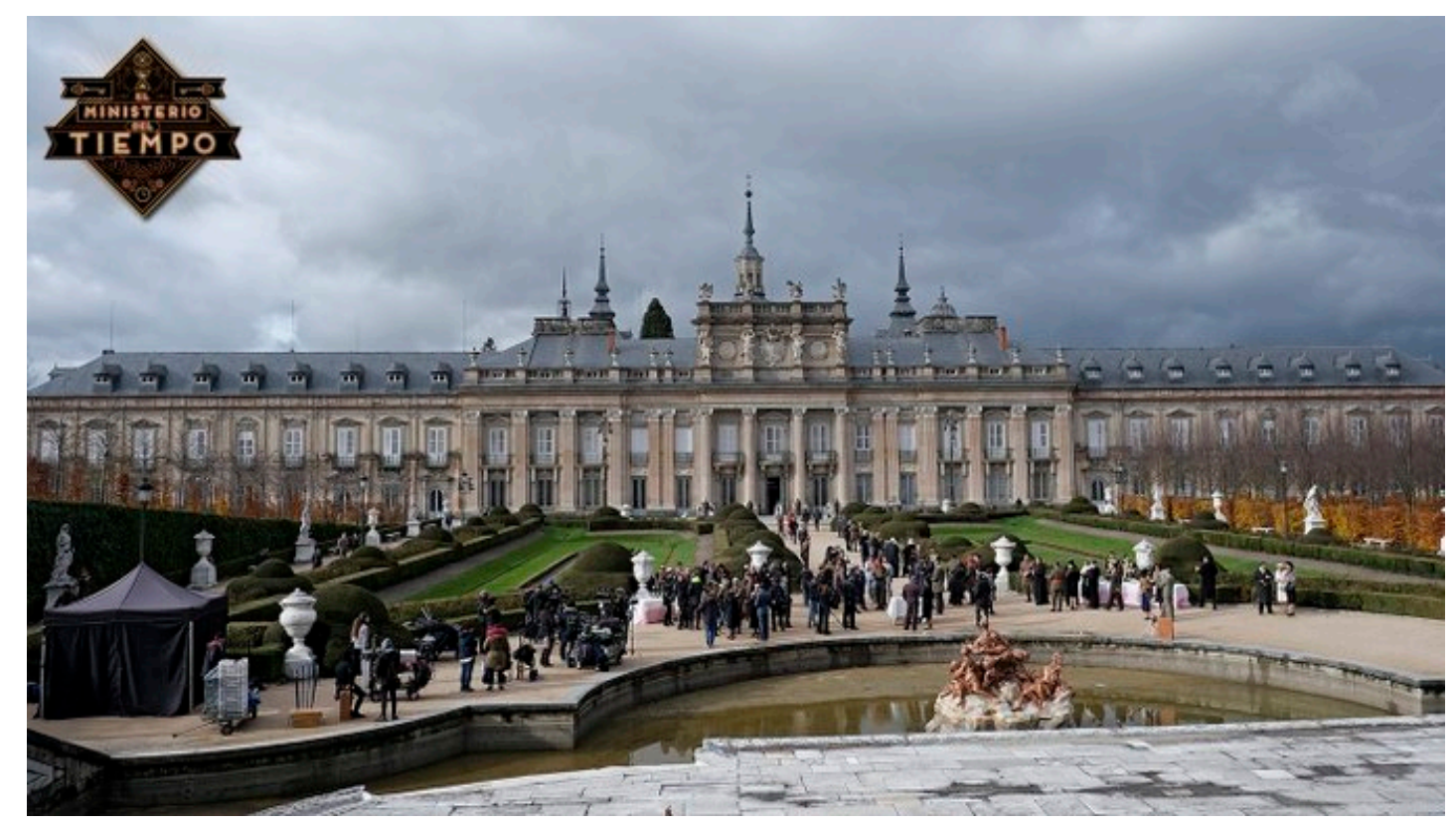

Fotografía de un día de grabación en el Palacio Real de la Granja de San Ildefonso. (C) Twitter El Ministerio del Tiempo

¿Qué ha significado para ti que EMDT tenga un enfoque más cultural/patrimonial, en comparación a otras series históricas como por ejemplo Timeless?

Timeless si se basa en un patrimonio histórico, en el de Estados Unidos. Lo que pasa es que está hecha como con prisa. Nosotros teníamos un concepto cultural basado en la historia, pero como ellos no tenían tiempo, empezaron a narrarlo como nosotros, y llegaban al minuto 30 y tenían que acabar cada 
argumento rápidamente. Además nosotros jugábamos con la ventaja de ser los originales y de ser una serie que tiene como referentes las primeras series históricas de Televisión Española, más las de la BBC, porque con mi hermano crecimos viendo la $\mathrm{BBC}$.

A mí me choca lo sucedido con Timeless, porque a su mando estaban Kripke y Ryan, que son dos guionistas a los que he admirado siempre, y en ese sentido sí se nota un poco que no supieron desarrollar el modelo en su terreno de acción. En nuestro caso hay algo por debajo de la historia que es la melancolía, y la tristeza, nuestra serie tiene sentimientos de pérdida de aquello que se tuvo y que no se ha sabido valorar, aquellas gentes que murieron pronto y que quieres imaginarte cómo sería si hubieran seguido viviendo. En ese sentido nuestra serie es más adulta.

\section{El patrimonio en la pantalla}

\section{Las ficciones históricas han sido bien acogidas por los jóvenes, ¿Por qué crees que esto ha sucedido?}

No lo sé. El boom de las series se dio después del auge de las televisiones públicas. Las nórdicas crecieron mucho; las alemanes siempre han estado produciendo o co-produciendo; y la BBC como maestra de todos. Luego llegó el concepto $\mathrm{HBO}$ con el poder de darle al creador el peso de la decisión final de las series. A partir de allí, muchas se han convertido en series de vanguardia cultural, en series de una época. Sobre la cima y el éxito de estas series como Los Sopranos, The Guardian, Breaking Bad, etcétera, surgen las plataformas y obras maestras como The Hunter, y The Crowm que son una maravilla histórica. Y de repente ves que se ha creado un nuevo mainstream, que no está respetando ciertos códigos que han hecho grande a las series, en el sentido del showrunner de HBO, o del creador como alguien literario que firma primero en la BBC. Me refiero al peso de lo culto, de la historia.

Una serie tiene como primera obligación entretener, pero no tiene que conformarse con eso. Hoy en día el mainstream se basa en producciones que me recuerdan mucho a las televisiones en abierto de hace 20 años. Creo que 
las series están empezando a cambiar y dejando de ser multigeneracionales. Se está haciendo una especie de briefing global en el cual se mira el famoso algoritmo. Y hay que recordar a la gente que el algoritmo es una función matemática, puede ser dos más dos, pero es muy distinto a que sean dos manzanas más dos manzanas a que sean dos coches más dos coches, porque en uno tienes cuatro manzanas y en otro tiene cuatro coches. El algoritmo es el mismo, pero la ética del algoritmo y la estética es otra. Estamos volviendo a entrar en el terreno en donde antes se decía "tu serie la tiene que entender la señora de Cuenca", como diciendo estás escribiendo muy profundo y el público no te va a entender. Pero el público es muy inteligente. El nosotros sabemos lo que te va a gustar me parece muy peligroso.

\section{¿Cómo se deben ver las series históricas?}

Al Ministerio cada generación la vede una manera diferente. Un amigo que visitó la Casa de España de Moscú me contó que los descendientes de exiliados de la guerra todavía ven la serie con lágrimas en los ojos porque ven la imagen de la España que ellos tienen en la cabeza. En los colegios, los niños y las nuevas generaciones de jóvenes la ven como una serie de aventuras, que es lo que en realidad. Entonces hay muchas capas, y cada generación la ve de la manera que quiera verla.

\section{En cuanto a las temáticas históricas ¿Cómo es el proceso de planificación?}

Nosotros hacemos una batería de temas, y vemos cómo podemos incluir a nuestros protagonistas en esas historias. iA veces no es posible! Luego vemos la producibilidad, poder rodar en relación a ello y mostrar ese tema. Depende mucho de sí sabemos coger el clic de la historia que tenemos que contar. A veces no podemos, no llegamos a tener ese brillo, esa idea. Unas veces se da esa peculiaridad, y otras veces es al revés, descubrir cosas que la gente no conoce. 


\section{En relación al contenido artístico y el patrimonial en EMDT, existe} un gran interés por retratar los grandes pintores españoles como Goya, Picasso o Velázquez, ¿Cómo se construye desde la ficción su identidad?

En el caso de Picasso estaba muy claro, porque había mucha documentación. Para Goya utilizamos como excusa un concepto. Así hicimos dos capítulos para hablar de una corriente estética en lugar de un momento histórico: en el caso de Goya fue la Ilustración y en el caso de Bécquer el romanticismo. Yo creo que una serie jamás ha hecho capítulos basados en corrientes estéticas para que la gente entienda este tipo de conceptos. Por otra parte, de Velázquez no se sabe casi nada a nivel biográfico. Es un personaje hermético que denota cierta sobriedad y mucha ambición por ser el apostador de la Corte. Ese concepto de ambición y de cortesano del lado del poder nos daba mucho juego para inventarnos cosas. Ahí fue donde casi más atrevidos hemos sido, utilizándolo como personaje cómico. Hemos convertido a alguien que es todo seriedad (uno de los mejores pintores de la historia del arte), en un personaje ególatra y cómico, y creo que nos ha salido muy bien. Ahora, mucha gente que piensa en Velázquez piensa en Julián Villagran y es que la imagen de los personajes históricos son la cara de nuestros actores. Y eso justamente es todo, porque la escena de Velázquez entrando en el Museo del Prado fue una apuesta ganadora.
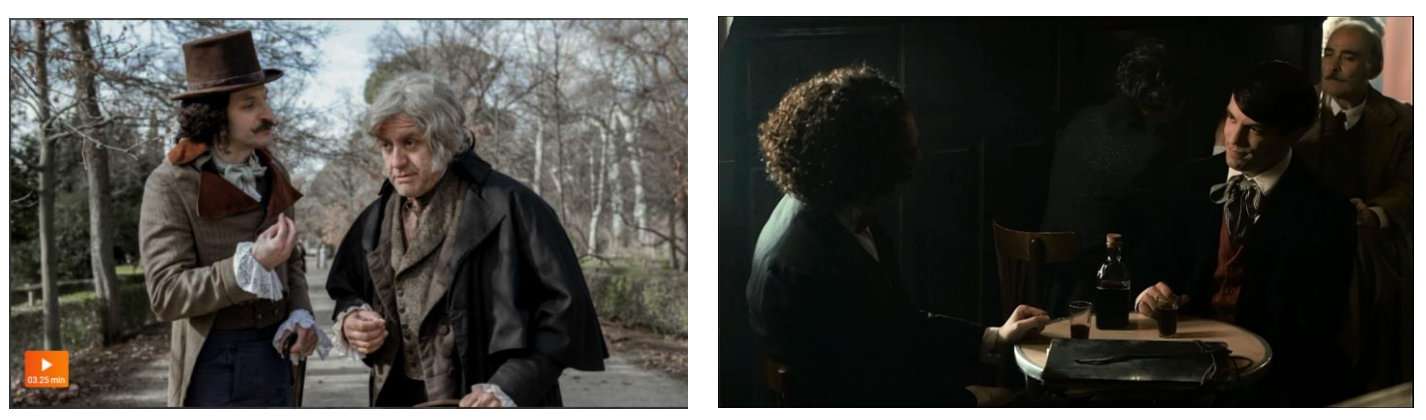

Fotogramas de la Serie El Ministerio del Tiempo. Encuentro de Diego Velázquez con Pablo Picasso (Temporada 1) y Francisco de Goya (Temporada 3). @ RTVE 
Teniendo en cuenta esa repercusión en las redes sociales, el Trending Topic que posicionó a la serie en boca de todos. ¿Cómo surgió la idea de fusionar la música de Christian Flores con Velázquez en El Prado y frente a las Meninas?

Eso es mérito de Christian Flores. Recuerdo que cerramos la tercera temporada y a los 20 días vi en Youtube el "Velázquez yo soy Guapa” y me dije «si hay otra temporada meto eso en el Prado». iY se ha conseguido, no! No se sí el hecho de la fuerza de Velázquez ha ayudado también a que Christian pensará en ese trap, pero es una dialéctica que sale fluida y que me vino hecha. Ahora el riesgo de mezclarlo, de poner a Velásquez a bailar un trap, es un riesgo que asumo. Como decía antes, EMDT es una serie pop de aventuras que mezcla historias con lo fantástico, es apropiación de imágenes y de personajes, descontextualización e ironía. Todos ellos son elementos del Arte Pop, del año del International Group de Londres, de Richard Hamilton, y de Liechtenstein. Esos mismos códigos son los que yo utilizo. Pero lo pop siempre ha sido bastante despreciado en España. De hecho ha habido grandes lagunas debido evidentemente a los muchos años de dictadura en la que la ironía, la imagen viva, la alegría no tenía mucha razón de ser. Incluso, en parte, cuando surge el Equipo Crónica por ejemplo se lo mira por encima del hombro, y cuando surge Almodóvar, una cultura pop evidente, es masacrado.

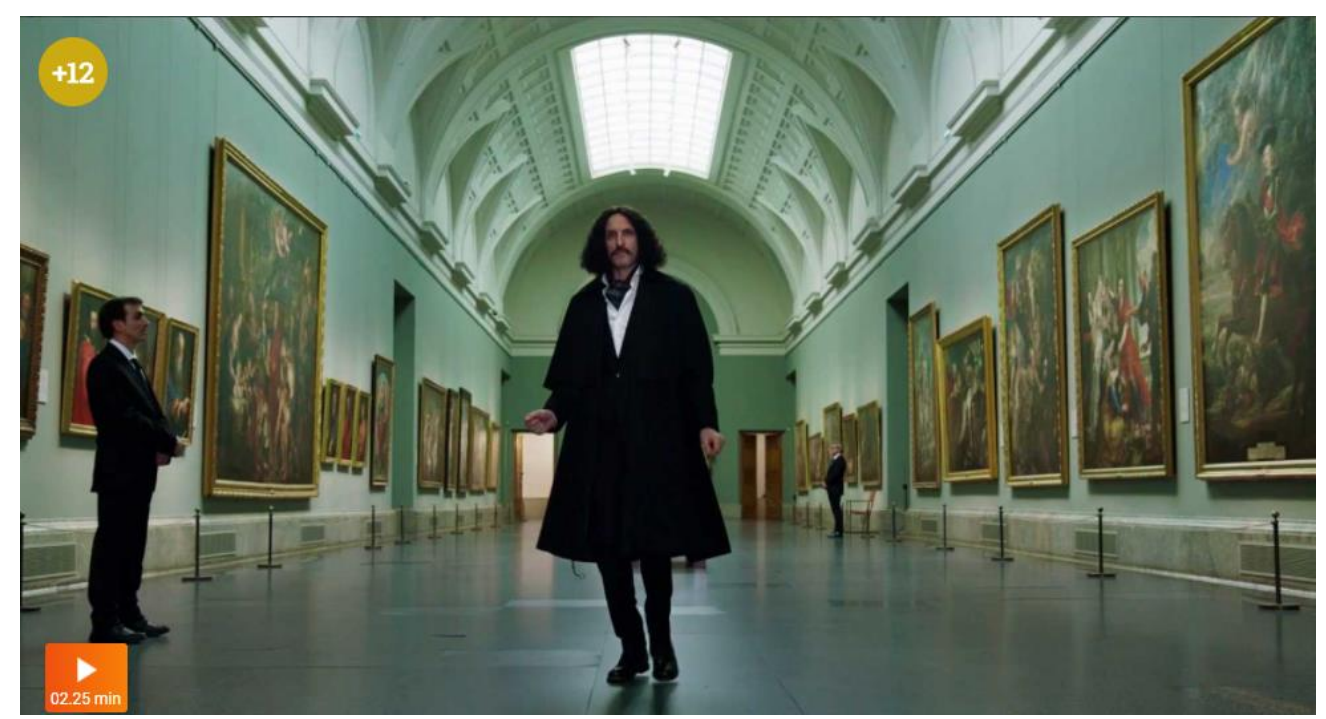

Fotograma tráiler oficial El Ministerio del Tiempo (Temporada 4, capítulo 38: La memoria del tiempo). La dialéctica de la obra del arte. (C) TVE 


\section{¿Piensas que la historia del arte salió ganando en este sentido?}

iCreo que el Museo del Prado tiene per se suficiente prestigio como para necesitar de nosotros! Pero creo que sí, hemos ayudado y, sobre todo, nos ha ayudado mucho, sobre todo la Biblioteca Nacional que ha estado twitteando cada capítulo ayudándonos a popularizar los personajes en las redes sociales. Me hizo mucha ilusión que Patrimonio Nacional en su anuncio de vuelta a las actividades [tras el estado de alarma producto de la pandemia del coronavirus] haya utilizado nuestra serie. En este sentido algo de orgullo si se tiene, y estoy muy satisfecho.

Tengo la intuición de que cuando pasen cinco, diez, incluso veinte años la gente se acordará de Curro Jiménez y de las series históricas de nuestra televisión. Pocas series se van a recordar tanto como EMDT. Tengo esa certeza porque forma parte de nuestro patrimonio cultural del cual he hablado, y porque de que de las nuevas generaciones que han entrado en el territorio de la aventura a través de nuestra serie, van a surgir un director, un guionista, un novelista que va a continuar esa misión. Estoy convencido de que cuando pasen los años, muchas de esas series que en algún momento fueron "series del año" se olvidarán y que EMDT se recordará, como se recordará Isabel.

\section{Las pantallas ocupan un lugar esencial de nuestra vida ¿Es importante dar a conocer el patrimonio y la historia a través de series como EMDT?}

A mí me importa que las audiencias conozcan las series, que las vean. Pero más allá del Ministerio lo que es importante es que la gente sepa quiénes son, en qué país viven, de dónde vienen y que la historia no empieza cuando ellos nacen. Hay que pensar que si en España no se hubiera expulsado a los judíos, ahora mismo estaríamos en otra España. Si siguiera existiendo la Constitución del 12, de la Pepa ${ }^{3}$, si no se hubiera dejado volver a Fernando

\footnotetext{
${ }^{3}$ La Constitución de 1812 es conocida popularmente como "La Pepa". El pueblo la denominó de manera coloquial así porque fue promulgada el 19 de marzo de 1812, día que se celebra la festividad de San José.
} 
VII esto sería otra España. Es decir, la historia tiene que volver a nuestras vidas, porque nuestro mundo sería completamente distinto si hubieran pasado otras cosas. Creo que ese patrimonio histórico y cultural es importante.

Un país que no sabe de dónde viene y cuál es su pasado, no conoce ni siquiera el presente y se convierte en un país ágrafo, inculto. $\mathrm{Y}$ eso es un gran peligro. Me parece muy importante generar una conciencia crítica, curiosidad, y para ello se debe estimular una serie de conocimientos. Y me ha pasado muchas veces sobre todo con seguidores argentinos y mexicanos, que yo decía “ipero cómo pueden ver la serie si está llena de clics muy culturales?". Creo que se trata de una calidad diferente de seguidores. Muchos me decían: «Hombre, es que al principio la disfruto como una aventura, pero luego ya la conozco y la vuelvo a ver y la disfruto el doble ».

EMDT es una serie para curiosos, y creo que ha nacido para generar una respuesta crítica a la ignorancia.

\section{Para finalizar, si pudieras rodar una quinta temporada del Ministerio ¿Qué patrimonio o historia te gustaría abordar?}

¡Muchas!... He dejado muchos temas pendientes. El problema es con qué las cuento, porque verdaderamente la cuarta temporada sí tiene un final definitivo. Yo quería cerrarla porque no podemos estar estirando los personajes eternamente, además llega un momento en que necesito defender la independencia narrativa de mi serie. Si hubiera una quinta temporada tengo temas, lo que no tengo es plan, y para ese plan necesito algo que no he tenido hasta ahora que es seguridad, un equipo estable, unos actores con los que quieres contar, y que las cosas tengan sobretodo una garantía, la de no bajar el nivel. O sea, no digo que no vuelvan los actores que están, pero sí que no serían los protagonistas básicos. Y todo eso es industria, producción, y un trabajo muy arduo que yo necesitaría que se me asegurara, porque EMDT es la serie más dura y difícil que he hecho y que haré jamás. Estoy muy orgulloso de ella, aunque quema mucho. Siempre estoy como un 
sonambulista, con un paraguas y abajo el vacío. Hasta ahora no me he caído, bueno... icreo que no me he caído!, y si no me he agarrado del cable...

\section{Referencias bibliográficas}

Berger, P. L., Luckmann, T., Zuleta, S. \& others. (1968). La construcción social de la realidad (Vol. 975). Amorrortu Buenos Aires.

Castoriadis, C. (2007). La Institución Imaginaria de La Sociedad. Tusquets Editores. Recuperado de https://bit.ly/36hEiQj

Leyton-Rivas, R. (2007)., El Patrimonio Cultural en la Formación del Periodista Revista Re Presentaciones: Periodismo, Comunicación $Y$ Sociedad. 2, 107-114. https://doi.org/https://bit.ly/2Xgi5i6 